\title{
В.В. Лещинская*
}

\section{ФОРМИРОВАНИЕ ЭКОЛОГИЧЕСКОЙ КУЛЬТУРЫ В УСЛОВИЯХ ГЛОБАЛИЗИРУЮЩЕГОСЯ МИРА: ЭСТЕТИЧЕСКИЙ АСПЕКТ}

\begin{abstract}
В статье рассматривается история становления и развития экологической эстетики как научной дисциплины, затрагиваются основные проблемы, связанные с этим процессом. Понятие экологической эстетики как нового направления философской рефлексии предполагает анализ его отличия от классической темы природы в искусстве и от эстетики окружающей среды. Автор фокусирует внимание на проблеме эстетизации природной среды как основополагающем структурном элементе формирования и развития эколого-эстетической культуры личности.
\end{abstract}

Ключевые слова: экологическая эстетика, экологическая культура, постнеклассическая рациональность, экологическое образование

The formation of environmental culture in the globalized world: an aesthetic aspect. VERONIKA V. LESHCHINSKAYA (Information-Analytical Center for Specially Protected Natural Areas Support)

The article discusses the history of the formation and development of environmental aesthetics as a scientific discipline and addresses the main problems associated with this process. The concept of environmental aesthetics as a new direction of philosophical reflection involves an analysis of its differences from the classical theme of nature in art and from the aesthetics of the environment. The author focuses on the problem of aesthetization of the natural environment as a fundamental structural element in the formation of the environmental and aesthetic culture of an individual.

Keywords: environmental aesthetics, environmental culture, post-non-classical rationality, environmental education

Обострившиеся взаимоотношения человека и природы демонстрируют свой предельный уровень, выход за который грозит человечеству не только его собственной гибелью, но и гибелью всей планеты. Катастрофические последствия техногенной цивилизации заставляют ученых различных областей и всю мировую общественность начать поиски истинных причин экологического кризиса, а также путей решения этих системных проблем.-Экологический и тесно с ним связанный антропологический кризисы требуют разработки абсолютно новой концепции экологической культуры. Само понятие «антропологический кризис» было сформулировано еще в 1920-х - 1930-х гг. в связи с негативными тенденциями в европейской культуре,

* ЛЕЩИНСКАЯ Вероника Владимировна, начальник отдела информационного обеспечения и методологии экологического просвещения и взаимодействия с общественными организациями Информационно-аналитического центра поддержки заповедного дела.

E-mail: ecometodist@mail.ru

(C) Лещинская В.В., 2019 
о чем писали К. Ясперс, К. Манхейм, Х. Ортега-и-Гассет, О. Шпенглер и др. В наши дни проблема человека становится особо острой, учитывая глобальные мировоззренческие и социальные изменения, а также духовно-нравственную нестабильность в обществе. Именно поэтому на первый план философских размышлений сегодня выходит антропологическая составляющая в контексте формирования экологической культуры как единственно возможной формы перехода к устойчивому развитию цивилизации и важного условия гармонизации отношений природы и человека.

Экологическая культура «предполагает беспрецедентную по сложности и масштабам переориентацию всех видов человеческой деятельности, в первую очередь тех, которые исторически сложились как разрушительные для природной среды. Изменение ориентации деятельности связано с коренной перестройкой мировоззрения, прежде всего той шкалы ценностей, которая укоренилась в сознании людей под воздействием противостояния человека природе. Иными словами, предстоит основательная ломка ценностей как материальной, так и духовной культуры и формирование новой - экологической культуры» [2, с. 80]. Многими учеными подчеркивается особая роль аксиологического подхода в решении проблемы формирования экологической культуры. В этом направлении философской мысли работали Е.Ю. Ногтева, Э.В. Гирусов, А.Н. Захлебный, И.Д. Зверев, И.Т. Суравегина, Т.П. Южакова. Аксиологический подход позволяет не только взглянуть по-новому на ценность природы, но и понять мотивацию формирования природосообразного отношения человека и природы. В настоящей статье будет заострено внимание на эстетической составляющей формирования целостного, экологического мировоззрения, которое невозможно без эстетически-нравственного подхода.

«Способность видеть эстетическое, прекрасное в природе, чувствительность к нему - вот некая предпосылка затем появляющегося этического отношения», - так считал известный психолог-теоретик и философ С.Л. Рубинштейн, изучающий проблемы развития психики, мышления, сознания и становления личности человека [9, с. 122]. В.И. Вернадский полагал, что ключевую роль в формировании ноосферы играют «сознание, культура и особенно искусство, соотносимые с художествен- ным построением мира на основе внутренней гармонии его процессов» [7, с. 35]. Ноосфера (от греч. noos - разум) Вернадского, разумно управляемая человеком на основе гармонизации отношений цивилизации и природы, представляет собой новый этап развития биосферы. Для нас особенно примечательно, что философ определил ключевую роль искусства в формировании нового ноосферного мировоззрения. Стоит упомянуть в этой связи направление русского космизма, которое вместе с учением В.И. Вернадского развивало мысль о незаменимой роли искусства и культурно-природного сближения в гармоничном познании природы. В трудах этих философов мы видим тенденцию к усилению темы природы, особого ее раскрытия средствами искусства через формы художественного переосмысления объектов природного мира. Таким образом, восприятие природы как самоценного эстетического объекта в парадигме экологической культуры является одним из путей гармонизации взаимоотношений человек-природа.

Во многих международных документах (в «Повестке дня на XXI век», в «Стратегии по образованию в целях устойчивого развития» и др.) также подчеркивается значимость развития духовных ценностей человека и установления гармоничных отношений с окружающим миром. Именно поэтому эколого-эстетическое направление в философии является перспективным, о чем говорят многие исследователи экологической эстетики - как зарубежные (Х. Янг, Ж. Мак Дермотт, Ю. Сепанма и др.), так и российские (Л.П. Печко, Н.Б. Маньковская, А.К. Шульженко и др.). Становление «человека экологического» [13], «чувственного существа», стоит как задача тысячелетия в противовес «человеку экономическому» Адама Смита. Фундаментальной характеристикой «человека экологического», человека новой формации, является реализуемый им эстетический опыт любования природой. Восприятие природы с точки зрения эколого-эстетического направления философской мысли имеет существенные отличия от традиционного рассмотрения темы природы в искусствоведческих дисциплинах и в философии искусства. Выделение в самостоятельную область научного знания и стремительное развитие экологической эстетики как многоаспектной междисциплинарной области научного знания тесно связано с общей проблематикой формирования экологической культу- 
ры, поиском новых методологических подходов в экологическом образовании и просвещении.

Эстетика - это область знания о неутилитарном созерцательном или творческом отношении человека к действительности, изучающая специфический опыт ее освоения, в процессе (и в результате) которого человек ощущает, чувствует, переживает в состояниях духовно-чувственной эйфории, восторга, неописуемой радости, блаженства, катарсиса, экстаза, духовного наслаждения свою органическую причастность к Универсуму в единстве его духовно-материальных основ, свою сущностную нераздельность с ним [6, с. 456]. В данном определении подчеркивается специфика эстетического освоения действительности через особое переживание своего личностного, эмоционально окрашенного отношения, причастности к Универсуму, к миру в целом. Необходимость четкой дефиниции экологической эстетики как научной дисциплины очевидна, так как восприятие природы как эстетического объекта является предметом пристального изучения многих наук: философии искусства, искусствоведения, эстетики, психологии, культурологии. Экологическая эстетика же имеет свое предметное поле, в которое включают и эстетическое освоение природы, и развитие эколого-эстетического (см.: [7, с. 30]). Между тем, проблематика формирования экологической эстетики, по мнению Л.П. Печко, недостаточно изучена и требует более пристального внимания в контексте актуальности становления экологического воспитания. Именно поэтому социально важным и своевременным является научное обоснование и развитие экологической эстетики как самостоятельной области научного знания. Вместе с тем междисциплинарность современной науки экологии и взаимообусловленность экологических проблем заставляет рассматривать экологическую эстетику также с позиции системного, коэволюционного подхода. По мнению исследователя Л.П. Печко, много лет занимающейся вопросами эстетики, культуры и эколого-эстетической педагогики, формирование экологической эстетики происходит на стыке проблематики социальной экологии и культуры.

Эстетическое в действительности проявляется в первую очередь через взаимодействие, через особое отношение. Для формирования экологической эстетики этот принцип приобретает особую важность. А.К. Шульженко подчеркивает необходимость рассмотрения «нового качества культурной коммуникации общества и природы, когда Человек и Природа рассматриваются как равнозначимые ценности, на передний план выдвигаются идеи гармонии, гуманизации, коэволюции, диалога, сотрудничества и компромисса в отношениях с природным миром, что возможно лишь на основе совершенствования чувственно-эстетических ориентаций личности» [12, с. 6]. Экологическая эстетика, начавшая свое активное развитие вместе с осознанием надвигающейся экологической катастрофы к концу ХX в., перестает быть дисциплиной, относящейся только к одному направлению научной мысли. Задача современных исследователей состоит в разработке концептуально нового философского подхода к эстетике природы с учетом изменений в научной картине мира. Можно выделить гносеологическую, аксиологическую, деятельностную и чисто эстетическую функцию особого восприятия природы в условиях переходного периода.

Существенную роль в обозначении предметно-проблемного поля экологической эстетики сыграли научные споры «природников» и «общественников». Имеются также другие обозначения этих научных направлений - «когнитивизм» и «нонкогнитивизм», проявившихся особо ярко в западной эстетике. Представителями «когнитивного» направления в философском мире являются М. Бадд, Г. Парсонс, М. Итэн, А. Карлсон, Ю. Сайто, Ю. Сепанма, К. Уолтон, Дж. Фишер, а сторонниками «нонкогнитивного» - А. Берлеант, Э. Брейди, С. Годловитч, Н. Кэрролл, Р. Хепберн и др. (см.: [1]). Для приверженцев «когнитивизма» главное в эстетике - знания о природе, которые являются ключевыми в оценке любого природного объекта, в то время как сторонники «нонкогнитивизма» считают основополагающим самоценность природы, то есть нечто отличное от когнитивного компонента. Два этих направления не вступают в противоречие друг с другом, а лишь исходят из различных отправных точек научной рефлексии. Основной пункт, который подчеркивают исследователи экологической эстетики, - это признание самоценности природы вне зависимости от установок познающего субъекта.

Однако, в контексте смены мировоззренческих ориентиров и преодоления экологического кризиса, эстетизация природного мира - это в первую очередь борьба с потребительским ми- 
ровоззрением современного общества. Принятие самоценности, эстетической привлекательности любого природного объекта меняет наше восприятие природы как окружающей среды, служащей практическим, утилитарным целям человека. Любой природный объект начинает восприниматься как эстетически привлекательный. Одинаковые по силе эстетические чувства может вызывать как красивый цветок, так и паук, крыса, змея и т. д. Восприятие природы в экологической эстетике уравнивает природные объекты в их эстетической ценности. В научный обиход начинает входить новое понятие «экологический идеал», который, по мнению А.К. Шульженко, выражает «эмоционально-чувственное представление о совершенстве окружающего мира» [12, с. 6].

Происходит пересмотр категорий «прекрасное» и «безобразное» в экологической эстетике. Последствия загрязнения всей биоты Земли, мощного антропогенного воздействия очевидны настолько, что, применяя категории эстетики, их можно отнести к сфере безобразного, тогда как все естественное, природное - к сфере прекрасного, красивого. Таким образом, классическая эстетическая дихотомия прекрасное-безобразное соотносится с категориями природного-антропогенного. Мы видим, что в современной эстетике (к примеру, постмодерна) стали видоизменяться критерии классических эстетических ценностей прекрасного, красивого, с одной стороны, а с другой стороны - безобразного, некрасивого. Многие исследователи экологической эстетики считают, что пришло время рассматривать все искусственное как отрицательно окрашенное, а все относящее к естественному - положительно. Исследователь Л.А. Закс считает, что «под экологической эстетикой тут понимается не наука об эстетических ценностях природной и культурогенной среды, их социокультурных основаниях и функциях, a ее реальный объект: эстетическое состояние этих основных сред “обитания” человека» [1, c. 42]. Другой исследователь, Н.В. Койнова считает, что «современная экологическая эстетика в целом направлена на поиск общечеловеческих ценностей в природопользовании, общественной жизни, технике и искусстве» [3, с. 54]. В таком случае «предметом экологической эстетики оказывается именно эстетическое освоение природы и гармонизация отношений субъекта деятельности к природному объекту на основе восприятия, переживания и оценивания его эстетических характеристик как объективных и универсальных» $[7$, с. 38].

Вместе с тем экологическая эстетика ставит перед исследователями и другую задачу, а именно задачу смены гносеологического статуса природного объекта в системе «человек-природа», которая требует также конкретизации и философского развития. Эколого-эстетическое отношение к миру предполагает уравнивание в познавательной ситуации природного объекта, человека и другого человека. Если рассматривать человека как часть природы, в таком случае он является равноценным природным объектом и в равной степени относится к предмету изучения эстетической экологии. Об отсутствии дистанции между наблюдателем и естественным объектом в экологической эстетике пишут многие, в частности - финский исследователь Ю. Сепанма, который полагает, что именно поэтому «эстетическая позиция трудна и не самоочевидна» [10, с. 234]. «Эстетическое восприятие среды ведется реципиентом изнутри самой среды», - таково мнение представителей «нонкогнитивного» лагеря западной экологической эстетики [8]. Стирание границ между субъектом и объектом познания, создание таким образом новой познавательной парадигмы выводит принципы экологической эстетики в поле постнеклассической методологии и задает определенное направление для формирования экологической культуры.

В период масштабных исторических трансформаций последних лет, в первую очередь в социальной, культурной сфере, в пространстве индивидуально-личностных изменений, в совокупности с глобальными вызовами современности происходит пересмотр и качественное изменение отношения к ценностным смыслам, которые дает нам природа. Сама по себе экологическая эстетика в контексте современных исследований представляет собой более широкую область знания, чем эстетика природы или эстетика окружающей среды. На наш взгляд, экологическая эстетика включает в себя восприятие всего окружающего человека мира: природного, в том числе культурно созданного, технократического. В современном познавательном контексте встает вопрос о том, что считать окружающей средой. Если исходить из того, что в центре рассматриваемой системы находится человека, то, безусловно, окружающая среда - это все, что окружает человека. В этот круг входят и природные объекты, и объекты, 
искусственно созданные цивилизацией. В таком контексте эстетика окружающей среды, на наш взгляд, включает в себя различные объекты изучения. Философ А. Берлеант, к примеру, считает, что экологическая эстетика - это «целенаправленное применение эстетических ценностей и принципов к вопросам повседневной жизни, деятельности и объектам, которые служат определенному практическому назначению, от одежды и автомобилей к лодкам, зданиям и поведению» (Цит. по: [1, с. 48]). Данное определение наглядно демонстрирует существующую терминологическую путаницу в определении понятия экологической эстетики.

Экологическая эстетика, на наш взгляд, - это в первую очередь эстетика гармонизации отношений человека и природы, процесс особой коммуникации между ними (см.: [4; 8]). Мы наблюдаем постепенное введение в теоретический и методологический оборот следующих терминов: «ценностное отношение к природе», «эмоционально-ценностное отношение», «личностное отношение к природе», «субъектное отношение к природе», что подчеркивает важность развития именно этого направления в экологической культуре и экологической эстетике. Природа - это целостный эстетический объект, ценность которого неразрывно связана с другими ценностями - моральными, религиозными и т. д. И это - еще один штрих, отличающий экологическую эстетику и от исследования темы природы в искусстве, и от философии природы в искусстве. Самоценность природного объекта, его равноценность с любым культурным объектом является отличительной черной нового эколого-эстетического рассмотрения системы человек-природа. Современные философские изыскания в этой области предполагают связь эколого-эстетических переживаний с сочувствием всему живому, с идеями ответственности перед жизнью как таковой. Эти идеи развивал еще в первой половине XX в. Альберт Швейцер.

Экологическая эстетика сопряжена с чувством ответственности перед любым природным объектом, на этом строится критерий эко-сознательной, зрелой личности. Понимаемая в таком ключе, экологическая эстетика находит все больше точек соприкосновения с экологической этикой: и та, и другая «исходят из принципа полноты, согласно которому культура призвана не только разрушать, но и созидать то, что не под силу природе; умножая эстетическое богатство натуры и культуры как целостности»
[10, с. 342]. В этом смысле культура не противостоит природе, но помогает человеку осознать ее самоценность. Здесь мы видим определенные основания для отказа от привычной дихотомии цивилизации и природы. В сферу экологической эстетики начинают включаться новые культурные традиции на основе морального, религиозного и социального опыта.

Эстетическое восприятие природы является одним из ключевых факторов, формирующих гармоничную личность, критерием ее зрелости и всестороннего развития. Умение видеть красоту и эстетическую самодостаточность природного объекта - условие формирования эколого-сознательной, развитой личности. Перед исследователями в настоящее время остро встает проблема эстетизации природной среды как основополагающего структурного элемента формирования и развития эколого-эстетической культуры личности, проблема эстетизации экологического образования и воспитания. В отечественной научной литературе исследований в этом направлении не много, в первую очередь здесь необходимо упомянуть работы Л.П. Печко, А.К. Шульженко, И.Ф. Смольянинова, Д.Х. Хацкевич. «Практическая эстетика подразумевает создание и апробирование новых методик по эколого-эстетическому развитию личности в контексте формирования экологической культуры, экологического образования и воспитания. Эколого-эстетическое воспитание - одна из областей эстетического воспитания, возникающая на стыке педагогики, психологии, искусствознания, общественных и естественных наук», - таков ход мыслей отечественных теоретиков эстетики природы [11, с. 343].

В настоящее время ведутся поиски актуальных методик развития личности на основе любования природой, развития чувственного восприятия природных объектов, формирования субъективно-эмоционального отношения. В экологической эстетике происходит гармоничное сближение культуры и природы на основе вне-рационального, эмоционально-интуитивного постижения реальности. Осознание целостности мира требует от субъекта познания новых познавательных практик. Складывается основа для нового, современного рационализма [5]. В настоящее время выделяется тенденция рассмотрения экологической эстетики как составной части общего процесса формирования экологической культуры, тесно связанного с антропологическими проблемами. С конца 1990-х гг. получила развитие такая 
самостоятельная научная дисциплина, как экологическая психология, исследующая психологические и психолого-педагогические основы взаимоотношений природы и человека. Эстетические переживания природы также относятся к сфере научных интересов экологической психологии.

Именно поэтому воспитание особого «чувства природы», своей природной сопричастности - первостепенная задача современной педагогики. В последнее время, к примеру, развивается прием эмпатии как методическая техника преодоления собственной субъективности, переживания Мира, усиления чувственного познания, снятия дуального противопоставления «Я» - «не Я» в отношении к природным объектам. Применяя рассматриваемый термин «эмпатия» к изучению проблемы формирования экологической культуры, исследователь выходит за пределы психологической науки и сталкивается с проблемой сознательного «вчувствования» и одновременно со-переживания и со-участия с природным объектом. Это то самое понятие «чувствование», которое формируется как со-чувствие (Г. Коген). Его «самочувствие есть любовь, но не самолюбовь, а любовь самости человека, которая становится природой человека... только и исключительно через искусство» (Цит. по.: [1, с. 4]).

Таким образом, задача науки эстетики в период конвергенции в научном мире, как отмечает В.В. Прозерский, «превратиться из философии искусства в философию среды человеческой жизни» [8], которая в свою очередь включает и природную среду как неотъемлемую часть. «Классическая эстетика созерцания должна уступить место эстетике вовлеченности» [8]. На основе чего должна осуществляться эта вовлеченность? На наш взгляд, вовлеченность предполагает как физическую включенность в процесс, так и эмоционально-психологическую связь с природным объектом. Данный подход был представлен в истории философии в разных вариантах: это и идея вчувствования (Т. Липпс), и идея бытия-в-мире (М. Хайдеггер), это и целый ряд сначала экзистенциалистских, а затем постструктуралистских идей. «В рамках каждого из этих подходов, - как полагает А.Е. Радеев, - возможно проследить становление нового понимания эстетики в целом и экологической эстетики в частности» [1, с. 53].

Любование природой - это процесс чувственного познания мира, неотделимого от рационального познания мира и включенного в общую систему познавательных ориентиров личности. Практическая эстетика ставит актуальный вопрос нового эколого-эстетического воспитания, где по-новому проблематизируются субъектно-объектные отношения, поскольку именно в экологической эстетике происходит слияние субъекта и объекта, субъект оказывается внутри исследуемого объекта, в системе природных взаимосвязей. Процесс вчувствования в природный объект дает возможность человеку лучше понять как самого себя (в качестве части природы), так и природу (как систему взаимосвязей между природными элементами). В этом ключе можно говорить о том, что экологическая эстетика как новое восприятие природы и человека становится феноменом развертывания и демонстрации постнеклассических принципов рациональности, положенных в основание формирования экологической культуры. Рассмотрение новых теоретических подходов к экологическому воспитанию должно учитывать эколого-эстетическую направленность, вопросы развития эколого-эстетической культуры личности, которые поднимались в трудах Д.С. Лихачева, С.Н. Глазачева, С.С. Кашлева и др. Кроме того, чувственно-эмоциональное познание окружающей среды имеет универсальные основы, способствующие эффективному сближению ценностных установок Запада и Востока, стиранию границ познавательных ориентиров людей разных культур, формированию мультикультурного пространства и поиску совместных решений глобальных проблем человечества.

\section{СПИСОК ЛИТЕРАТУРЫ}

1. Актуальная эстетика - I. Тезисы докладов межвузовского научного форума 10-11 октября 2013 г. СПб.: Санкт-Петербургское философское общество, 2013.

2. Гирусов Э.В. Экологическая культура как высшая форма гуманизма // Философия и общество. 2009. № 4. С. 74-92.

3. Койнова Н.В. Роль экологической эстетики в развитии эколого-эстетических норм современного общества // Приволжский научный вестник. 2012. № 1. С. 53-57.

4. Маньковская Н.Б. Эстетика постмодернизма. СПб.: Алетейя, 2000.

5. Моисеев Н.Н. Современный антропогенез и цивилизационные разломы. Эколого-политологический анализ // Вопросы философии. 1995. № 1. С. 3-30. 
6. Новая философская энциклопедия: в 4-х т. Т. 4. М.: Мысль, 2010.

7. Печко Л.П. Выразительность эстетики природы и культура личности. Ульяновск: УлГТУ, 2008.

8. Прозерский В.В. Научный обзор литературы по экологической эстетике [Электронный ресурс]. - Режим доступа: http://aesthetics. philosophy.spbu.ru/ecolobzor/

9. Рубинштейн С.Л. Бытие и сознание. Человек и мир. СПб.: Питер, 2003.

10. Хацкевич Д.Х. Природа как эстетическая ценность. М.: Высш. шк., 1987.

11. Эстетика природы / под ред. К.М. Долгова. М.: ИФ РАН, 1994.

12. Шульженко А.К. Эколого-эстетическое воспитание молодежи в европейской и отечественной педагогике: автореф. дисс. ... д-ра пед. наук. М., 2006.

13. Meinberg, E., 1998. Environmental destruction: a philosophical-anthropological perspective. URL: http://www.bu.edu/wcp/Papers/ Anth/AnthMein.htm

\section{REFERENCES}

1. Aktual'naya estetika - I. Tezisy dokladov mezhvuzovskogo nauchnogo foruma 10-11 oktyabrya 2013 g. [Relevant aesthetics - I. Abstracts of the Inter-University Scientific Forum. October 10-11, 2013]. Sankt-Peterburg: Sankt-Peterburgskoe filosofskoe obshchestvo, 2013. (in Russ.)

2. Girusov, E.V., 2009. Ekologicheskaya kul'tura kak vysshaya forma gumanizma [Ecological culture as the highest form of humanism], Filosofiya $\mathrm{i}$ obshchestvo, no. 4, pp. 74-92. (in Russ.)

3. Koinova, N.V., 2012. Rol' ekologicheskoi estetiki $\mathrm{V}$ razvitii ekologo-esteticheskikh norm sovremennogo obshchestva [The role of environmental aesthetics in the development of environmental and aesthetic values of modern society], Privolzhskii nauchnyi vestnik, no. 1, pp. 53-57. (in Russ.)

4. Man'kovskaya, N.B., 2000. Estetika postmodernizma [Aesthetics of postmodernism]. Sankt-Peterburg: Aleteiya. (in Russ.)

5. Moiseev, N.N., 1995. Sovremennyi antropogenez i tsivilizatsionnye razlomy. Ekologopolitologicheskii analiz [Modern anthropogenesis and civilizational rifts. Analysis from the point of ecology and political science], Voprosy filosofii, no. 1, pp. 3-30. (in Russ.)

6. Novaya filosofskaya entsiklopediya: v 4-kh t. T. 4 [New philosophical encyclopedia: in 4 volumes. Vol. 4]. Moskva: Mysl', 2010. (in Russ.)

7. Pechko, L.P., 2008. Vyrazitel'nost' estetiki prirody i kul'tura lichnosti [The expressiveness of the aesthetics of nature and personality culture]. Ul'yanovsk: U1GTU. (in Russ.)

8. Prozerskii, V.V. Nauchnyi obzor literatury po ekologicheskoi estetike [Review of research in environmental aesthetics]. URL: http://aesthetics. philosophy.spbu.ru/ecolobzor/ (in Russ.)

9. Rubinshtein, S.L., 2003. Bytie i soznanie. Chelovek i mir [Being and consciousness. Man and the world]. Sankt-Peterburg: Piter. (in Russ.)

10. Khatskevich, D.Kh., 1987. Priroda kak esteticheskaya tsennost' [Nature as an aesthetic value]. Moskva: Vyssh. shk. (in Russ.)

11. Dolgov, K.M. ed., 1994. Estetika prirody [Aesthetics of nature]. Moskva: IF RAN. (in Russ.)

12. Shul'zhenko, A.K., 2006. Ekologoesteticheskoe vospitanie molodezhi v evropeiskoi i otechestvennoi pedagogike [Environmental aesthetic education of youth in European and Russian pedagogy], avtoreferat dissertatsii doktora pedagogicheskikh nauk. Moskva. (in Russ.)

13. Meinberg, E., 1998. Environmental destruction: a philosophical-anthropological perspective. URL: http://www.bu.edu/wcp/Papers/ Anth/AnthMein.htm

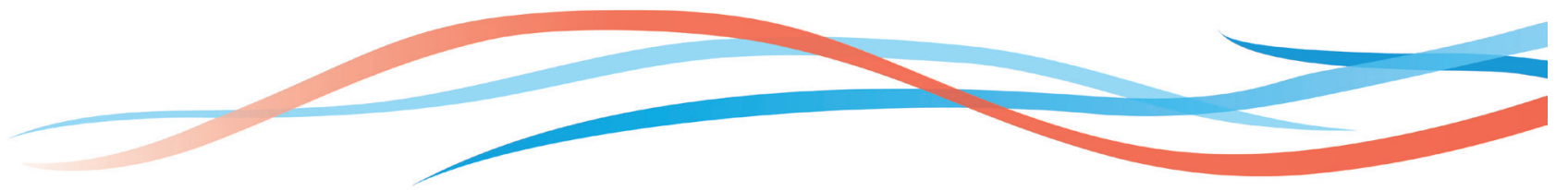

